\title{
CYANOSIS AS A GUIDE TO ARTERIAL OXYGEN DESATURATION
}

\author{
BY \\ W. E. MEDD,* E. B. FRENCH, AND V. McA. WYLLIE \\ From the Northern Group of Hospitals, Edinburgh, and the Department of Medicine, \\ University of Edinburgh
}

(RECEIVED FOR PUBLICATION MAY 25, 1959)

It is known that the presence or absence of cyanosis of warm parts is some guide to the level of arterial oxygen saturation. Comroe and Botelho (1947) exposed the limitations of cyanosis as a sign, but their observations were made in bright light on normal subjects, who inhaled decreasing percentages of oxygen in nitrogen. Some sites commonly used for the detection of central cyanosis, such as the tongue and inner lips, were not inspected, presumably for technical reasons. The present investigation set out to assess the reliability of cyanosis of various parts of the body as a guide to arterial oxygen desaturation in patients under ordinary ward conditions. An attempt has been made to explain such discrepancies as were discovered.

\section{MATERIAL}

Adult hospital in-patients (52 men and 20 women) were selected as having possible central cyanosis because on inspection by one of us this seemed possible, or because they were referred to us in response to a request for patients with probable central cyanosis. All the patients with arterial oxygen desaturation suffered from acute or chronic respiratory disease and none had veno-arterial shunts as far as is known. None were known to have abnormal pigments in the blood. Patients with a baemoglobin content of less than $11 \mathrm{~g}$. per $100 \mathrm{ml}$. were excluded.

\section{MeTHODS}

All the patients were examined by the three authors in turn, and the presence or absence of cyanosis of the nail bed, tongue, and inner and outer lips was independently recorded. When cyanosis was thought to be present, the observer tried to judge the percentage arterial oxygen saturation. After the first 30 patients the conjunctiva was also examined following a suggestion by Dr. I. W. B. Grant. Light intensity was measured approximately by an exposure meter (Weston Model 141) placed near the patient's

*Work done while acting as a locum physician to the Edinburgh Northern Group of Hospitals and temporary part-time

Department of Medicine. University of Edinburgh. face and pointed towards the middle of the ward. Some estimate of the quality of the light was obtained by repeating this measurement through red, green, and blue filters. Each patient was re-examined under the standard conditions of a portable floodlight. A heparinized sample of arterial blood was then taken and kept on ice ; its oxygen saturation was estimated by means of a haemoreflector within four hours of collection. The accuracy of the method was tested on arterial blood samples from 10 subjects who were free from respiratory and cardiac disease ; the results ranged from 93 to $99 \%$, with an average of $96.1 \%$. In addition duplicate specimens from eight patients in the series were submitted to the analyst under pseudonyms. The average difference between samples was $1.5 \%$ and once only (when it was $4 \%$ ) the difference was greater than $2 \%$.

Haemoglobin was estimated by the method of Evelyn and Malloy (1938).

\section{RESULTS}

AgreEment.-The percentage of patients in whom all three observers agreed on the presence or absence of cyanosis is shown for each site in Table I.

TABLE I

\begin{tabular}{|c|c|c|c|c|c|c|}
\hline \multicolumn{3}{|c|}{ AGREEMENT } & \multicolumn{2}{|c|}{ IN EACH } & \multicolumn{2}{|l|}{ SITE } \\
\hline Tongue & & & .. & .. & .. & \\
\hline & . & .. & .. & & & \\
\hline & $\therefore$ & .. & .. & .. & .. & \\
\hline unctiv & .. & . & $\cdot \cdot$ & . & $\cdots$ & $\begin{array}{l}54 \% \\
53 \%\end{array}$ \\
\hline & .. & $\cdots$ & & & & \\
\hline
\end{tabular}

It will be seen that even in the most favourable site, the tongue, there was agreement in only $69 \%$ of cases, while in the worst site, the nail bed, there was $53 \%$ agreement.

Arterial Oxygen Saturations.-In Table II the patients are divided into groups according to the laboratory estimation of arterial oxygen saturation.

TABLE II

GROUPING ACCORDING TO ARTERIAL OXYGEN SATURATION

\begin{tabular}{r|c|c|c|c|c|c|c}
\hline$\%$ Oxygen Saturation & $96-100$ & $92-95$ & $88-91$ & $84-87$ & $80-83$ & $76-79$ & 75 or \\
No. of Patients & 16 & 25 & 12 & 6 & 5 & 2 & 6 \\
\hline
\end{tabular}




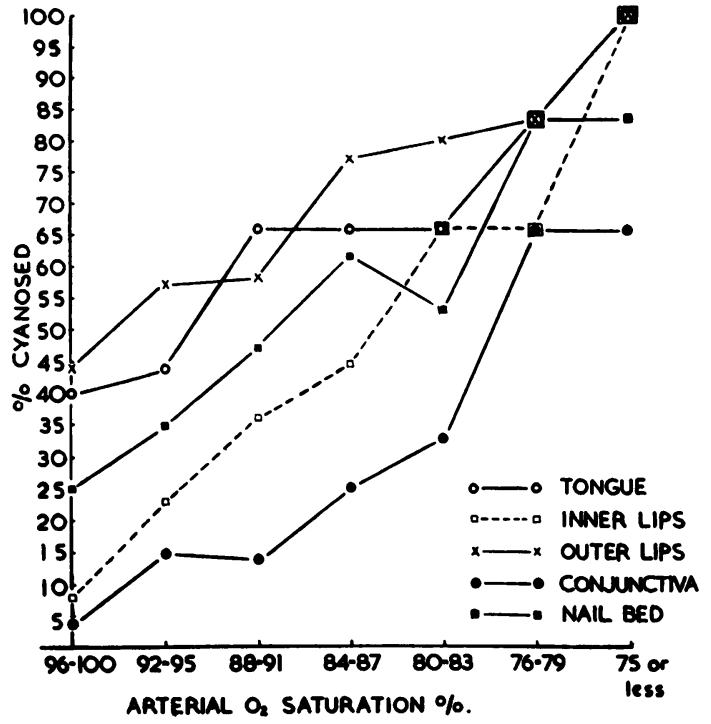

Fig. 1.-Frequency of cyanosis noted in each group at the site inspected.

Fig. 1 shows the frequency of cyanosis noted in each group at the sites inspected. There was a clear tendency for a progressively greater percentage of patients to be recorded as cyanosed in the groups with lower arterial saturation, but there were great differences in sensitivity between the sites. Thus the tongue and the outer lips showed the largest incidence of cyanosis when the saturation was low, but even at normal saturations cyanosis was recorded in 40 to $45 \%$ of patients. At the other extreme the conjunctiva and inner lips were infrequently noted as cyanosed at normal levels, but they were less reliable indicators of gross desaturation. The nail beds lay between these extremes. In none of the sites was cyanosis uniformly recorded unless the arterial saturation was $75 \%$ or less. From these observations it is difficult to choose the best site for the detection of central cyanosis, as the incidence of cyanosis of the various sites in unselected subjects with a normal arterial saturation is not known. The tongue has the advantages of a high measure of agreement (Table I) and sensitivity (Fig. 1) and it is the results at this site which are analysed in the remainder of this paper.

In Fig. 2 the observers' quantitative estimates of arterial oxygen saturation are plotted against the percentage of cases which had an actual saturation of $91 \%$ or less. As would be expected, greater degrees of cyanosis are more likely to represent significant desaturation. In the presence of gross cyanosis of the tongue, desaturation $\frac{0}{}$ ( $91 \%$ or less) was present on at least $85 \%$ of $\frac{\bar{D}}{\frac{\bar{D}}{(1)}}$ occasions.

In view of the imperfect correlation between the clinical and the laboratory estimation of $\%$ central cyanosis, three factors which might $\overrightarrow{0}$ reasonably be supposed to affect the accuracy of our observations have been investigated: (1) $\vec{\omega}$ The haemoglobin concentration of the patient's $\stackrel{\rho}{\Rightarrow}$ blood ; (2) the light under which the patients were $x$ inspected; and (3) observer deficiencies.

\section{HAEMOGLOBIN}

It has generally been accepted since the 은 observations of Lundsgaard and Van Slyke (1923) $-\vec{A}$ that the haemoglobin level has an important bear- $\mathbb{D}$ ing on the development of cyanosis. In the present $\frac{\vec{D}}{\mathbb{D}}$ series all patients whose haemoglobin was less than 3 11 g. per $100 \mathrm{ml}$. have been excluded. To test whether the haemoglobin concentration is a factor even above this level, two groups of patients were extracted from the whole.

(1) Those, 19 in number, whose arterialo saturation was $92 \%$ or more in whom cyanosis of the tongue was recorded by two or three observers (average $94.4 \%$ oxygen saturation). (2) Those, nine in number, whose arterial $\mathbb{\perp}_{2}^{\Phi}$ saturation was below $92 \%$ in whom the tongue $\Rightarrow$ was not cyanosed according to two or all three of us (average $87 \%$ oxygen saturation). If a high haemoglobin level favoured the development of cyanosis, then the figure for the first group should be significantly greater than the second. This, 0 however, was not the case, as it averaged $12.5 \%$ ine

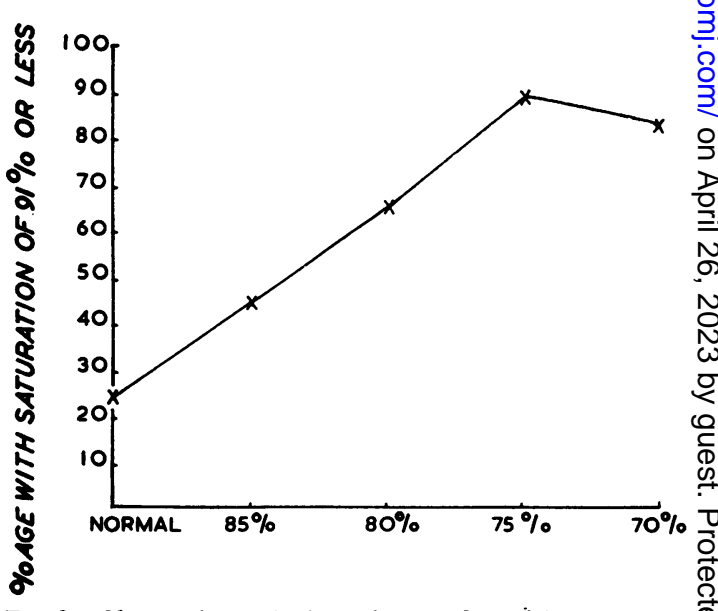

FIG. 2.-Observers' quantitative estimates of arterial oxygen satura $\vec{\Phi}$ tion plotted against the percentage of cases which had an actuaf saturation of $91 \%$ or less. 
the first and $12.4 \%$ in the second. It is concluded that variations in haemoglobin content from $11.1 \%$ to $16.5 \%$ did not contribute to the discrepancies.

\section{LIGHT}

- To assess any effect of light upon the results, the total number of patients examined was divided into two groups, those examined when the total light intensity was 20 or more candles per sq. $\mathrm{ft}$. (35 patients) and those examined when it was less than 20 (37 patients). In each group the average measurement through red and green filters was about equal at one-fifth of the total, while onetenth of the total intensity came through the blue filters. As the quality of the light showed no significant variation, only the total intensity was considered. The percentage who had cyanosis of the tongue in the two groups at different ranges of arterial saturation is shown in Fig. 3. There is less tendency to diagnose cyanosis in brighter lights in all ranges except those with saturations of $75 \%$ or below. In fact all the failures to diagnose cyanosis of the tongue in patients with saturations of $87 \%$ or below occurred when they were inspected in bright light. These findings are at variance with the statement of Comroe and Botelho (1947) that good lighting favoured the recognition of cyanosis at minor degrees of oxygen desaturation.

\section{ObSERVER Deficiencies}

Colour Vision.-Defective colour vision is a factor which might reduce an individual's

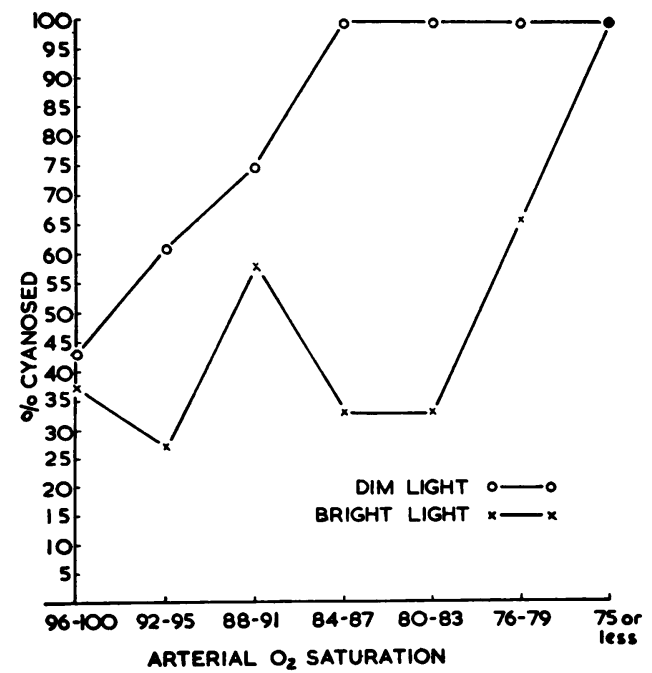

FIG. 3.-Percentage of patients with cyanosis of the tongue in two groups at different ranges of arterial saturation.

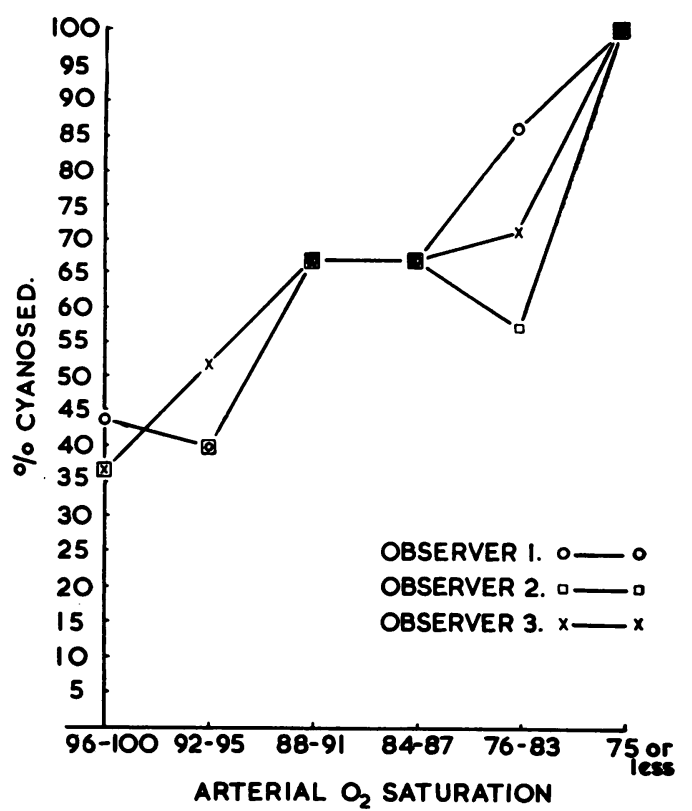

FIG. 4.-Performance of three observers at various saturations compared.

efficiency. The Ishihara and Dvorine tests showed that none of the three observers was a major redgreen defective. More detailed testing by the Pickford colorimeter (Pickford, 1951) showed that observer 3 was in the normal range. Observers 1 and 2 showed green deviation in the red-green test and both yellow and blue deviation in the yellow-blue test. The only considerable anomaly was the yellow deviation in observer 1 which was more than three times the standard deviation. The test is very exacting, e.g., the range of normal colour vision for yellow-blue only includes $68 \%$ of the population. To assess whether these differences in colour vision might be significant in the present investigation the performance of the three observers in diagnosing cyanosis of the tongue at various saturations was compared separately (Fig. 4). It will be seen that there is little difference between them. Greater degrees of colour blindness, which may be unknown to the observer, might, however, be the cause of error.

EFFECT of Practice.-Comparing the first half of the results with the second half showed insufficient change to conclude that practice resulted in a significant improvement.

Personal ERror.-There is considerable error between observers as evidenced by the lack of universal agreement on so many individual cases (see Table I). When the results of each observer 
are plotted for the whole group (Fig. 4) the agreement is reasonably close, especially for the larger groups in the higher ranges of saturation. This suggests that the error is random rather than due to inherent ability of any one individual.

\section{Discussion}

It is often stated that cyanosis of a warm part indicates central cyanosis. Our results for the tongue do not accord with this statement. The warmth of a part depends upon its metabolism, the surrounding temperature, the rate of evaporation from its surface, and its blood flow. If an extremity exposed to room temperature in a temperate climate is warm, its mean blood flow is high. The tongue is a warm part because it is protected from the surrounding atmosphere and it cannot be assumed that the blood flow through it is high.

Clinical cyanosis depends mainly upon the amount of reduced haemoglobin in the subpapillary venous plexus. The proportion of reduced haemoglobin tends to rise as the blood flow falls ; cyanosis then depends upon a sufficient pool of blood in the venous plexus. When the blood flow is high the part is usually warm and pink, but may be blue if a sufficiently sluggish superficial venous pool is present. An extreme example of this is seen in the so-called "portwine" naevus. Blood in the sublingual veins, like the retinal veins, often looks a little cyanosed, and it appears from our results that this colour may extend to the tongue without implying that central cyanosis is present.

\section{SUMmARY AND CONCLUSIONS}

The presence or absence of cyanosis of the tongue, the outside and inside of the lips, the conjunctiva, and the nail beds was recordeg independently by three observers on 72 patients suspected of having arterial oxygen desaturatiob

Although the incidence of cyanosis rose ift groups of patients with progressively lowe arterial saturation, cyanosis is an imperfect guide to desaturation, since it was not uniform recorded unless the saturation was $75 \%$ or less. $\vec{A}$

This imperfect correlation was partly due to random observer deficiencies, but errors occurres even when all observers agreed.

The tongue is probably the most sensitive site for the observation of central cyanosis, thougti cyanosis of the tongue does not necessarily indicate arterial oxygen undersaturation.

Cyanosis is best observed when the light is not too bright.

Our thanks are due to those physicians an $\bar{\phi}$ surgeons of the Edinburgh Northern Group of Hospitals who allowed us to study their patients:to Professor A. C. Dornhorst for helpful criticism; to Dr. R. M. Sillitto for his advice on light measure ment; to Professor R. W. Pickford and Mr. R Lakowsky for testing the authors' colour vision; 18 Miss N. Miller for the arterial oxygen determinations and to Drs. B. Tammas, G. Slavin, H. Barber, and D. G. Strachan for help with this investigation.

\section{REFERENCES}

Conuroe, J. H., Jr., and Botelho, S. (1947). Amer. J. med. Sci., 214 , Evelyn, K. A., and Malloy, H. T. (1938). J. biol. Chem., 126, 655. Lundsgaard, C., and Van Slyke, D. D. (1923). Medicine (Baltimore)

Pickford, R. W. (1951). Individual Differences in Colour Visiof p. 127. Routledge and Kegan Paul, London. 